\title{
Heavy metals detoxification: A review of herbal compounds for chelation therapy in heavy metals toxicity
}

\author{
Reza Mehrandish ${ }^{1}$, Aliasghar Rahimian ${ }^{2}$, Alireza Shahriary ${ }^{* * \mathbb{D}}$ \\ ${ }^{1}$ Chemical Injuries Research Center, Systems Biology and Poisonings Institute, Baqiatallah University of Medical Sciences, Tehran, Iran \\ ${ }^{2}$ Department of Medical Biochemistry, Tehran University of Medical Sciences, Tehran, Iran
}

\section{A R T I C L E I N F O}

Article Type:

Review

Article History:

Received: 30 December 2018

Accepted: 15 January 2019

\section{Keywords:}

Herbal plants

Heavy metals

Chelation

Detoxification

\begin{abstract}
A B S T R A C T
Some heavy metals are nutritionally essential elements playing key roles in different physiological and biological processes, like: iron, cobalt, zinc, copper, chromium, molybdenum, selenium and manganese, while some others are considered as the potentially toxic elements in high amounts or certain chemical forms. Nowadays, various usage of heavy metals in industry, agriculture, medicine and technology has led to a widespread distribution in nature raising concerns about their effects on human health and environment. Metallic ions may interact with cellular components such as DNA and nuclear proteins leading to apoptosis and carcinogenesis arising from DNA damage and structural changes. As a result, exposure to heavy metals through ingestion, inhalation and dermal contact causes several health problems such as, cardiovascular diseases, neurological and neurobehavioral abnormalities, diabetes, blood abnormalities and various types of cancer. Due to extensive damage caused by heavy metal poisoning on various organs of the body, the investigation and identification of therapeutic methods for poisoning with heavy metals is very important. The most common method for the removal of heavy metals from the body is administration of chemical chelators. Recently, medicinal herbs have attracted the attention of researchers as the potential treatments for the heavy metals poisoning because of their fewer side effects. In the present study, we review the potential of medicinal herbs such as: Allium sativum (garlic), Silybum marianum (milk thistle), Coriandrum sativum (cilantro), Ginkgo biloba (gingko), Curcuma longa (turmeric), phytochelatins, triphala, herbal fibers and Chlorophyta (green algae) to treat heavy metal poisoning.
\end{abstract}

Implication for health policy/practice/research/medical education:

This review showed that some medicinal herbs can be considered as the potential treatment for the heavy metals poisoning and regular consumption of these herbal products may significantly reduce the absorption of heavy metals.

Please cite this paper as: Mehrandish R, Rahimian A, Shahriary A. Heavy metals detoxification: A review of herbal compounds for chelation therapy in heavy metals toxicity. J Herbmed Pharmacol. 2019;8(2):69-77. doi: 10.15171/jhp.2019.12.

\section{Introduction}

Some heavy metals are nutritionally essential elements (such as: iron, cobalt and zinc) while, some of them are relatively harmful (ruthenium, silver, indium). Metals in second group, could be considered as potentially toxic elements in high amounts or certain chemical forms. Furthermore, some heavy metals (mercury, cadmium and lead) are highly toxic. Potential sources of poisoning with heavy metals are toilets, industrial wastes, agricultural runoff, occupational contacts and dyes (1). Heavy metals are present in the earth's crust in small amounts but there are used for making lots of tools like: mobile phones, plastics, cars and insecticides (2).
The biological effects of heavy metals have been known since ancient times. Some derivate of heavy metals such as arsenic, platinum and ruthenium are used as the anticancer agents. Also, antimony (anti-protozoa), bismuth (used for stomach ulcer), gold (anti-arthritis) and iron (anti-malaria) are other heavy metals used in medicine. In addition, copper, zinc, gold and silver are known as antiinflammatory compounds (3).

It has been reported that metals such as: cobalt, copper, chromium, iron, manganese, magnesium, molybdenum, nickel, selenium and zinc play important roles in different physiological and biological processes. Therefore, the lack of adequate supply of these elements could lead to various 
syndromes and diseases. Although there is no standard definition for heavy metals, it has been referred to a group of metals that have relatively high densities, atomic weights or atomic numbers. Bioavailability of heavy metals is affected by various chemical and physical factors such as temperature mechanism of absorption and physiological characteristics of the exposed species $(4,5)$.

As mentioned above, exposure to a number of heavy metals such as arsenic, cadmium, chromium, lead and mercury has harmful effects on human health. In the present study, first, the toxicity of harmful heavy metals and their molecular mechanism, which threatens human health and damage to various organs, has been reviewed. Further, the symptoms of poisoning with these metals have been described in order to clarify the importance of studying the therapeutic methods of heavy metal poisoning. Finally, the treatment methods for heavy metals poisoning have been discussed. Since medicinal herbs are recently considered by many researchers due to their fewer side effects than chemical compounds, we have reviewed the potential of medicinal herbs such as: Allium sativum (garlic), Silybum marianum (milk thistle), Coriandrum sativum (cilantro), Ginkgo biloba (gingko), Curcuma longa (turmeric), phytochelatins, triphala, herbal fibers and Chlorophyta (green algae) in the treatment of harmful heavy metals poisoning.

\section{Heavy metals toxicity}

Various usage of heavy metals in industry, agriculture, medicine and technology have led to their widespread distribution in nature raising concerns about their effects on human health and environment. The severity of toxicity arising from heavy metals, depends on various factors such as: dose, contact pattern, chemical species as well as age, sex, genetics and nutritional status of the person who is being contacted. Arsenic, chromium, cadmium, lead and mercury are important metals in relation to public health due to their high degree of toxicity. These metals are considered as systematic poisoning agents that can lead to organ failure even in exposure with lower dose. Hence, in recent years, concerns about public health and environmental pollution with these heavy metals are increased. Human exposure to heavy metals has been increased in recent decades due to their widespread usage in industry. Also, environmental contamination in mining, casting and other related industrial areas are very significant $(6,7)$.

Metallic ions may interact with cellular components such as DNA and nuclear proteins leading to apoptosis and carcinogenesis arising from DNA damage and structural changes (8). Laboratory research has shown that reactive oxygen species and oxidative stress play a key role in the toxicity and carcinogenicity of heavy metals such as arsenic, cadmium, chromium, lead and mercury. These metals have a significant effect on general health, because of their systematic toxicity which can damage multi system organs, even at low doses. Various heavy metals and their physiological effects in body are shown in Table 1 (9).

Arsenic, cadmium, chromium, lead and mercury significantly contribute to environmental pollution. These elements enter human body through ingestion, inhalation and dermal contact to cause several health problems such as, cardiovascular diseases, neurological and neurobehavioral abnormalities, diabetes, blood abnormalities and various types of cancer. The effects of these metals on human health depend on the type of metal and chemical type. Also these effects are time-dose dependent. Several studies have shown that exposure to heavy metals causes long-term problems on human health. Some of these metals cause both acute and chronic toxicities. Recent studies have reported that these toxic elements may interact with some physiologically important metals such as iron calcium and zinc, to impair their normal metabolic function (10).

\section{Arsenic exposure}

Arsenic is an element founding almost all environments in low concentrations. A large proportion of arseniccontaining compounds are manufactured industrially to be used in agriculture as pesticides, herbicides and fungicides. Also, these are used in veterinary to root out pumpkin worms in sheep and cattle herds. Arsenic compounds have long been used in medical sciences to treat diseases such as: syphilis, amoebic diarrhea and trypanosome $(11,12)$. Millions of people around the world appear to be constantly in contact with arsenic, especially in Bangladesh, India, Mexico and Taiwan, where ground water is contaminated with significant amount of arsenic. Arsenic pollution is a serious concern of public health. Several studies have found strong correlations between arsenic exposure and some pathological conditions including: cardiovascular diseases, peripheral vascular diseases, diabetes, hearing problems, blood abnormalities (anemia, leukopenia, and eosinophilia) and caner $(12,13)$.

\section{Cadmium exposure}

As a toxic trace element cadmium is highly capable of causing environmental and occupational hazard. Cadmium is widely used in battery industries and industrial workers dealing with this heavy metal are at high risk of cadmium poisoning through ingestion and inhalation which may damage digestive tract, lungs, liver and urethra and if severe, it can lead to coma and even death (14). Chronic exposure to cadmium suppresses norepinephrine, serotonin and acetylcholine levels and its inhalation triggers development of the pulmonary adenocarcinoma. Also, direct contact with cadmium can proliferate prostatic lesions including adenocarcinoma. There is evidence indicating that cadmium can damage 
Table 1. Physiological importance of heavy metals

\begin{tabular}{|c|c|}
\hline Metals & Biological significance \\
\hline Iron & Oxygen transportation; Plays a role in metabolism as a component of some proteins and enzymes. \\
\hline Zinc & $\begin{array}{l}\text { Participates in drug metabolism, in mobilizing vitamin A from the liver, and In a defense system in } \\
\text { microorganisms against free radical damages. }\end{array}$ \\
\hline Copper & $\begin{array}{l}\text { Plays an important role in our metabolism, is essential for maintaining the strength of the skin, blood vessels, it } \\
\text { epithelial and connective tissue throughout the body. }\end{array}$ \\
\hline Chromium & $\begin{array}{l}\text { Important in the metabolism of fats and carbohydrates. It stimulates fatty acid and cholesterol synthesis. Also, it } \\
\text { is involved in insulin action and glucose metabolism. }\end{array}$ \\
\hline Cobalt & An essential part of vitamin B12 and involved in hematopoiesis \\
\hline Molybdenum & $\begin{array}{l}\text { Act as an electron carrier in those enzymes that catalyzing the reduction of nitrogen and nitrate. Is needed for } \\
\text { at least three enzymes. Sulfite oxidase catalyses the oxidation of sulfite to sulfate, necessary for metabolism of } \\
\text { sulfur amino acids. }\end{array}$ \\
\hline Selenium & A functional mineral in immune system. \\
\hline Manganese & $\begin{array}{l}\text { Plays a Role in the Metabolism of macronutrients. It helps with protein and amino acid digestion and utilization, } \\
\text { as well as the metabolism of cholesterol and carbohydrates }\end{array}$ \\
\hline Magnesium & $\begin{array}{l}\text { It is important in energy production and maintaining electrolyte balance. Is essential for normal neuromuscular } \\
\text { functions as well as calcium and potassium transport }\end{array}$ \\
\hline \multicolumn{2}{|r|}{ Therapeutic effects } \\
\hline Arsenic, Platinum, Ruthenium & Anti-cancer \\
\hline Bismuth & Stomach ulcer \\
\hline Gold & Anti-arthritis \\
\hline Iron & Anti-malaria \\
\hline Copper, Zinc, Gold, Silver & Anti-inflammatory \\
\hline \multicolumn{2}{|r|}{ Harmful effect } \\
\hline Mercury & $\begin{array}{l}\text { Reduced sensory abilities, fatigue, anorexia, irritability and excitability, cardiovascular disease, hypertension } \\
\text { with renal dysfunction. }\end{array}$ \\
\hline Cadmium & Anemia, hair loss, hypertension, kidney problems \\
\hline Lead & $\begin{array}{l}\text { In children: delayed mental development, hyperactivity. } \\
\text { In adults: fatigue, anemia, metallic taste, loss of appetite, weight loss and headaches, insomnia }\end{array}$ \\
\hline Arsenic & Fatigue, headaches, dermatitis, increased salivation, muscular weakness, loss of hair and nails \\
\hline
\end{tabular}

DNA without free radical dependence. However, cadmium is less mutagenic than other metals $(15,16)$.

\section{Chromium exposure}

Chromium is known as a carcinogen and due to its widespread use in various industries, chromium can contaminate many of environmental systems. It is also found in industrial wastes. Occupational exposure is a major concern because of the high risk of chromiuminduced diseases in industrial environments where the people are in contact with chromium type VI (17). Known as toxic agents, chromium VI containing compounds can damage various organs resulting in different diseases such as: kidney damage, allergies, asthma and respiratory tract cancer in human. The most common health problems caused by chromium I in animals include stimulation of stomach ulcer, sperm damage and disorders of male reproductive system. The breakdown of DNA in peripheral lymphocytes and elevated lipid peroxidation products in the urine of chromium exposed patients, suggests that chromium VI could stimulate human poisoning (18).

\section{Lead exposure}

Lead has a severe toxic effect on multi organ systems including: liver, kidney, central nervous system and reproductive system. However, lead poisoning manifests with different complications in children and adults. There is a direct relationship between blood lead levels and decreased intelligence quotient, neurodegenerative deficits and hearing loss in children. Acute lead poisoning in adult persons triggers brain damage, kidney damage and digestive system diseases, while, chronic exposure to lead can affect blood cells, central nervous system, kidney and vitamin D metabolism. Also, lead enters bone structure, through combination with bone minerals. Evidences have shown that lead poisoning can stimulate cellular degradation through production of reactive oxygen species $(6,19)$.

\section{Mercury exposure}

Mercury is found in three forms in nature: elemental, organic and inorganic, all of which exhibit different behavior in terms of toxicity. Widely distributed in nature, mercury is a toxic element. This metal affects human health by causing severe changes in tissues (20). Due to its wide distribution in nature, exposure to some chemical forms of mercury is inevitable.

Due to very low excretion rate, a large percentage of 
absorbed mercury accumulates in kidneys, nerve tissue and the liver. All chemical forms of mercury are poisonous and cause gastrointestinal poisoning, neurological and kidney toxicities. Oxidative damages caused by mercury poisoning arise from accumulation of reactive oxygen species that are eliminated by normal antioxidants in normal state. Mercury stimulates the formation of reactive oxygen species, causing DNA damage and carcinogenesis $(21,22)$.

\section{Heavy metal toxicity treatment}

The first step in treatment of heavy metals poisoning, is to eliminate the source of exposure and to keep the patient away from the exposure source. The first-line therapy is symptomatic and supportive treatment and to make sure that the monitoring is carried out on various organs of the body including kidney, liver, respiratory and cardiovascular systems. Administration of chelating agents is the most common therapy. (23).

Recently medicinal herbs have attracted the attention of researchers as the potential treatments for the heavy metals poisoning. Some herbs contain chelating agents which reduce the bioavailability and gastrointestinal absorption of heavy metals. Moreover, herbal treatments can decrease the bioavailability of toxic substances by increasing the gastrointestinal movements resulting in faster excretion of toxicants through the feces. This can be considered as an auxiliary method to reduce the effects of poisoning with heavy metals if ingestion is the rout of exposure. According to previous findings, regular consumption of herbal products, may significantly reduce the absorption of heavy metals (24).

\section{Roles of chelation in natural toxicokinetics}

Not only animals, but also plants produce some chelating compounds. Metallothionein content of foods may affect the bioavailability and metabolism of toxic metals such as cadmium. Metallothioneins are a superfamily of cysteine-rich, low-molecular-weight metalloproteins that bind heavy metal ions. These cytosolic metallopeptides thought to be involved in metal homeostasis, metal detoxification and oxidative stress protection, can reduce the gastrointestinal absorption and renal reabsorption of toxic metals and also stimulate detoxification processes $(25,26)$ :

1. Fibers in food products, such as cereals and fruits, can be used as a chelating therapy, along with the main treatment, in order to cut off enterohepatic recirculation.

2. There are also some other natural polymers which are reported to be the potential absorbent of heavy metals, like algal polysaccharides alginate, chlorella and citrus pectin.

3. Since toxic metals have a high tendency to bind to sulfur containing peptides, a diet rich in foods containing sulfur such as alliums (A family of plants that include garlic and onion) and brassicas (like broccoli) are used to improve symptoms of poisoning and increase the removal of heavy metals from the body.

4. Cilantro (Coriandrum sativum) is a popular culinary and medicinal herb.

\section{Medicinal herbs effective in treatment of heavy metals poisoning}

Key herbs which can act in this way including Allium sativum (garlic), Silybum marianum (milk thistle), Coriandrum sativum (cilantro), Ginkgo biloba (gingko), Curcuma longa (turmeric), Phytochelatins, triphala, herbal fibers and Chlorophyta (green algae) are briefly discussed below:

\section{Allium sativum}

Allium sativum is an herbal medication containing allin, as its main amino acid. Allin contains sulfur substitutes and in the presence of alliinase is converted to allicin, which then produces other compounds such as: vinyldithiines, ajaenes, and poly sulfides (27). Sulfur components are responsible for the smell created by garlic. Allium vegetables, such as garlic, onion, leek and chive, contain organosulfur compounds contributing to clearance of heavy metals such as lead and arsenic by the liver. Also, cruciferous vegetables, such as broccoli, cauliflower, cabbage, kale, Brussels sprouts, turnips, and kohlrabi are rich sources of sulfur-containing substances.

\section{Garlic}

Garlic has been used as an herbal medication throughout ancient and modern history to prevent and treat a wide range of conditions and diseases. Based on evidences, in the Middle East and East Asia, garlic has been used to treat bronchitis, hypertension, tuberculosis, liver disorders, intestinal worms, rheumatism, diabetes and fewer. Garlic is reported to be a wonderful medicinal plant owing to its preventive effects against cardiovascular diseases, lowering blood sugar and cholesterol levels, effective against bacterial, viral, fungal and parasitic infections.

Heavy metals can damage the tissues through indirect induction of oxidative stress. It has been shown that garlic has a protective effect on the liver. It has the high effect on poisoning caused by cadmium, mercury and lead, respectively (28).

Onion and garlic could be used as an alternative remediation to increase clearance of toxic heavy metals such as arsenic, cadmium, iron, mercury and lead. Garlic is rich in vitamin C, vitamin B6 and manganese. Organosulfur compounds specially and allicin, are biologically active ingredients providing the main protective capabilities of garlic. These components could contribute to detoxification of heavy metals since they are 
able to bind to most of chemical compounds harboring positive charges.

Garlic shows a protective effect against heavy metals poisoning in mice and co-administration of garlic with cadmium or organic mercury for 12 weeks reduces the accumulation of heavy metals in the liver, kidneys, bones and testicles (target organs of cadmium poisoning). Also, it has been shown that regular garlic consumption reduces the histopathological damages and inhibit serum alkaline phosphatase enzyme. Garlic at the higher dosage causes a decrease in mercury accumulation in the brain in animals treated with methyl mercury. This protective effect is because of a smaller amount of mercury absorbed into the brain as a result of the increased excretion of mercury from the body by garlic. The protective effect of garlic is probably caused by sulfur compounds combining with the heavy metals in the body and promoting excretion through bile to the feces. Studies have also shown that the absorption of garlic through the respiratory tract can limit the effect of lead (29).

\section{Milk thistle}

Milk thistle which is also known as Silybum marianum is native to Europe, the Middle East, North Africa, and parts of the Mediterranean region. However, it can be found around the world. Milk thistle history is quite vast. Humans have used milk thistle for more than 2000 years. In ancient Greece the doctors have recommended milk thistle tea as a remedy for snakebites. In the sixteenth century, the English herbalist John Gerard has mentioned milk thistle as an anti-depressant herbal in his "Anatomy of Plants". In the seventeenth century, physician and herbalist Nicolas Culpeper claimed that milk thistle can help the liver by unblocking it, when the bile ducts blocked, bile builds up in the liver and jaundice developed due to increasing level of bilirubin in the blood, so it also helps to cure jaundice. Milk thistle has been used as an herbal medication all over the world. Many of early botanists and pharmacists in ancient Greece and Rome have used milk thistle to aid bile-related problems, which, as we know, are liver-related complications. Also, in traditional Chinese medicine, milk thistle belongs to the category of herbs that clears heat and relieves toxicity. Herbs in this category are used to clear infections, which are referred to as internal heat in traditional Chinese medicine.

Silybum marianum contains flavonoids such silybin, silychristin, silydianin and 2,3 dehydro derivatives (30). Oral silybin consumption, especially silybin- $\beta$ cyclodextrin, protects liver against iron-induced toxicity in mice. Silybin treatment reduces the accumulation of additional malondialdehyde-altered proteins in peritoneal portal hepatocytes (reduces oxidative and lipid proxidative damages).

Silybin also reduces liver function impairments. Protective properties of Silybin are possibly explainable by its notable iron binding ability.

A group of Italian researches have reported the silybin content for Iron binding (silybin is a component of the silymarin or flavonolignan complex). This complex is found in milk thistle.

The study was designed to find an oral and nonsynthetic alternative for synthetic iron-binding agent "Desferrioxamine" because this drug has side effects like: bone deformation, sensory impairment and toxicity. These researchers found that silybin bound to ferric iron, strongly even in acidic $\mathrm{pH}$. Regarding its bioavailability silybin seems to have potential to increase the excretion of heavy metals (24).

In addition, the simultaneous consumption of vitamin $\mathrm{C}$ (ascorbic acid) and silymarin, results in more improved detoxification of lead by rats liver. In patients with liver problems arising from toluene and xylene, silymarin could improve liver function (31).

\section{Cilantro}

Cilantro (Coriandrum sativum) is a plant native to Mediterranean region of Europe. Cilantro has been used for at least 5000 years. The cilantro seeds, also known as coriander, has been found in ancient Egyptian tomb. Coriander has been used in the treatment of male infertility. The Chinese people have used cilantro for centuries. The ancient Egyptians used coriander tea to treat clinical conditions such as urinary tract infections and headaches.

Several studies have been conducted to investigate the potential of cilantro in detoxification of heavy metals. Results of two published studies suggest that this plant could help improve mercury clearance in a number of patients poisoned with heavy metals. However, these studies showed that cilantro established a weaker bond with heavy metals in comparison to allicin of garlic and silybin of milk thistle, indicating that its administration has less priority than garlic and milk thistle.

The results of another study showed that cilantro prevented localized placement of lead in mice. However, these results are remarkable for bone tissue and not for soft tissues. In other hand, the relationship between dose and response has not been observed so the presented results are not very reliable (24).

\section{Ginkgo biloba}

Ginkgo biloba, known as maidenhair tree (32), is a plant native to China and has various uses in traditional medicine. G. biloba extract is a standard extract of $G$. biloba leaves which exhibits anti-oxidant properties as the free radical scavenger in different organs providing protective benefits against sensory. It is a condition in which the brain has trouble receiving and responding to information that comes through the senses.

The results of the study by Tunali-Akbay et al, indicate 
that lead toxicity causes toxic effects on aorta and the heart which are associated with increased lipid peroxidation and decreased glutathione level.

Ginkgo biloba is one of the herbal remedies useful as a complementary treatment for lead-poisoned patients. $G$. biloba inhibits lead-induced poisoning and corrects the biochemical parameters. Also, G. biloba causes the free radicals to be trapped leading to reduced oxidative stress and elevated glutathione level.

Increased malondialdehyde production as a consequence of lead poisoning is well-documented. Results of studies show that G. biloba consumption, significantly suppresses lipid peroxidation and reduces the production of malondialdehyde which is the end product of lipid peroxidation (32).

\section{Turmeric}

Turmeric is the root of a plant which is scientifically known as Curcuma longa. While turmeric is perfectly safe and a wonderful spice, it isn't as useful to our body system as its component, curcumin. Curcumin is a naturally-occurring chemical compound found in the spice turmeric.

Curcumin is a bright yellow chemical agent produced by some plants. It is a member of ginger family, Zingiberaceae. Curcumin has been used historically in Ayurvedic medicine against various human diseases. Anti-hepatoxic effects of curcumin are well-documented and according to the literature, curcumin reduces liver toxicity caused by environmental toxicants such as arsenic, cadmium, chromium, lead and mercury. It prevents histological damage, lipid peroxidation and corrects glutathione level to retrieve the antioxidant capacity of liver and to protect the liver enzymes against oxidative stress. Most of the protective effects attributed to the curcumin arise from its ability to trap free radicals and its chelating property (32).

As indicated in the literature, dietary supplementation could be considered as a natural method for detoxification of heavy metals. Although time-consuming, supplementation with vitamin $\mathrm{C}$, chromium and garlic helps to clear metals from the body, and it does not show the side effects arisen from administration of chemical chelators.

The study by Hewlings and Kalman highlights two important biological properties of curcumin, one of them is anti-oxidant and the other one is anti-inflammatory effects. According to the results of these researchers, curcumin exerts its antioxidant effect by trapping free radicals and by adjusting the activity of catalase, glutathione and superoxide dismutase enzymes (33).

\section{Phytochelatins}

Phytochelatins are oligomers of glutathione, produced by the enzyme phytochelatin synthase. They are found in plants, fungi, nematodes and all groups of algae. Phytochelatins act as chelators, and are important for heavy metal detoxification. Phytochelatins composed of three amino acids: glutathione, cysteine, glycine (Glu, Cys, Gly), have been identified in many plant species and in some microorganisms. These compounds are reported to be involved in detoxification of cadmium. Nonetheless, there is little evidence indicating the efficacy of phytochelatins on detoxification of wide range of heavy metals (34). In this regard, studies have shown that phytochelatins can form complexes with lead, mercury and silver. The biochemical mechanism underlying detoxification of heavy metals by phytochelatins is very complicated. Briefly, increased concentration of metal ions triggers the activation of the enzyme phytochelatin synthase, then metal ions form complexes with phytochelatins followed by transfer into the vacuoles to form more complexes with sulfide groups and organic acids (35).

\section{Triphala}

Triphala (Emblica officinalis) is a traditional ayurvedic herbal formulation obtained from dried powder of three fruits: Amalaki (known as Bibitaki), Terminalia bellirica and haritaki. Triphala has been reported to exhibit anti-bacterial, anti-inflammatory, and anti-diarrheal activities (36). This traditional formula is able to improve the constipation and regulating the gastrointestinal movements that are important for the removal of heavy metals.

\section{Herbal fibers}

Herbal fibers play an important role in detoxification of heavy metals. The results of studies show that fiber consumption reduces the exposure to toxins due to increased gastrointestinal motility. Pectin is the most important plant fiber. It is a form of soluble fiber found in many fruits. Consumption of pectin-rich fruits in the diet contributes to improved digestion and owing to it high capability of pectin in binding heavy metals, can support the detoxification process. After ingestion pectin passes directly the stomach and intestine and reaches the colon. As negatively charged compounds, pectin fibers tend to attract the ions of heavy metals. Pectins reach out with their carboxylic groups and grab heavy metals, radionuclides, and bile acids to bind and carry these items out of our bodies, which helps reduce our toxic load.

\section{Green algae}

Green algae and some other aquatic plants are capable of absorbing mercury in the environment. It is reported that Chlorella in diet increases the clearance of mercury from the digestive tract, muscle, ligaments, connective tissue and bones (37). Chlorella is a green algae which due to its high chlorophyll content acts as a natural chelator of heavy metals, especially lead and mercury. Chlorella and cilantro as food materials can detoxify some neurotoxins such as heavy metals (example: mercury) and toxic chemicals (like: phthalates, plasticizers and insecticides) (38). 
Table 2. Detoxification features of the selected herbal plants

\begin{tabular}{lllll}
\hline No. & Scientific name & Family & Common name & Excreted heavy metals \\
\hline 1 & Allium sativum & Amaryllidaceae & Garlic & Lead, mercury, cadmium \\
2 & Silybum marianum & Daisy family & Milk thistle & Iron, lead \\
3 & Coriandrum sativum & Umbellifers & Cilantro & Mercury, lead \\
4 & Ginkgo biloba & Ginkgoaceae & Ginkgo & Lead \\
5 & Curcuma longa & Ginger family & Turmeric & Arsenic, cadmium, chromium, lead, mercury \\
\hline
\end{tabular}

Herbs scientific and common names, their families and specific heavy metals that are excreted by each of them, are given in Table 2 .

\section{Dietary considerations for detoxification of heavy metals}

The first step is to change the nutritional behavior and lifestyle for health promotion.

A plant-based diet beneficial for detoxification of heavy metals should include:

1. Green leafy vegetables: Green foods are one of the strongest foods to remove heavy metals. The results of the studies show that daily consumption of bitter vegetables such as cabbage, tomatoes, spinach and beet vegetables reduces the inflammation and has antioxidant properties.
2. Herbs and spices: Anti-inflammatory and antioxidant plants such as parsley, basil, Mentha pulegium (pune), rosemary, Thyme (avisen), ginger, turmeric, cinnamon and cilantro can contribute to improved clearance of heavy metals. Cilantro is a good herb to be consumed to remove heavy metals and can reduce the formation of heavy metals such as mercury and lead in the body (37).

3. Foods rich in vitamin C: Fruits and vegetables rich in vitamin $\mathrm{C}$ can reduce the damage caused by heavy metals poisoning owing to their antioxidant properties. Vitamin C-rich foods include: citrus, such as orange and grapefruit, green leaves like spinach and cabbage and also red pepper.

Figure 1 shows the mechanism of harmful effect of detrimental heavy metals in body and the subsequence

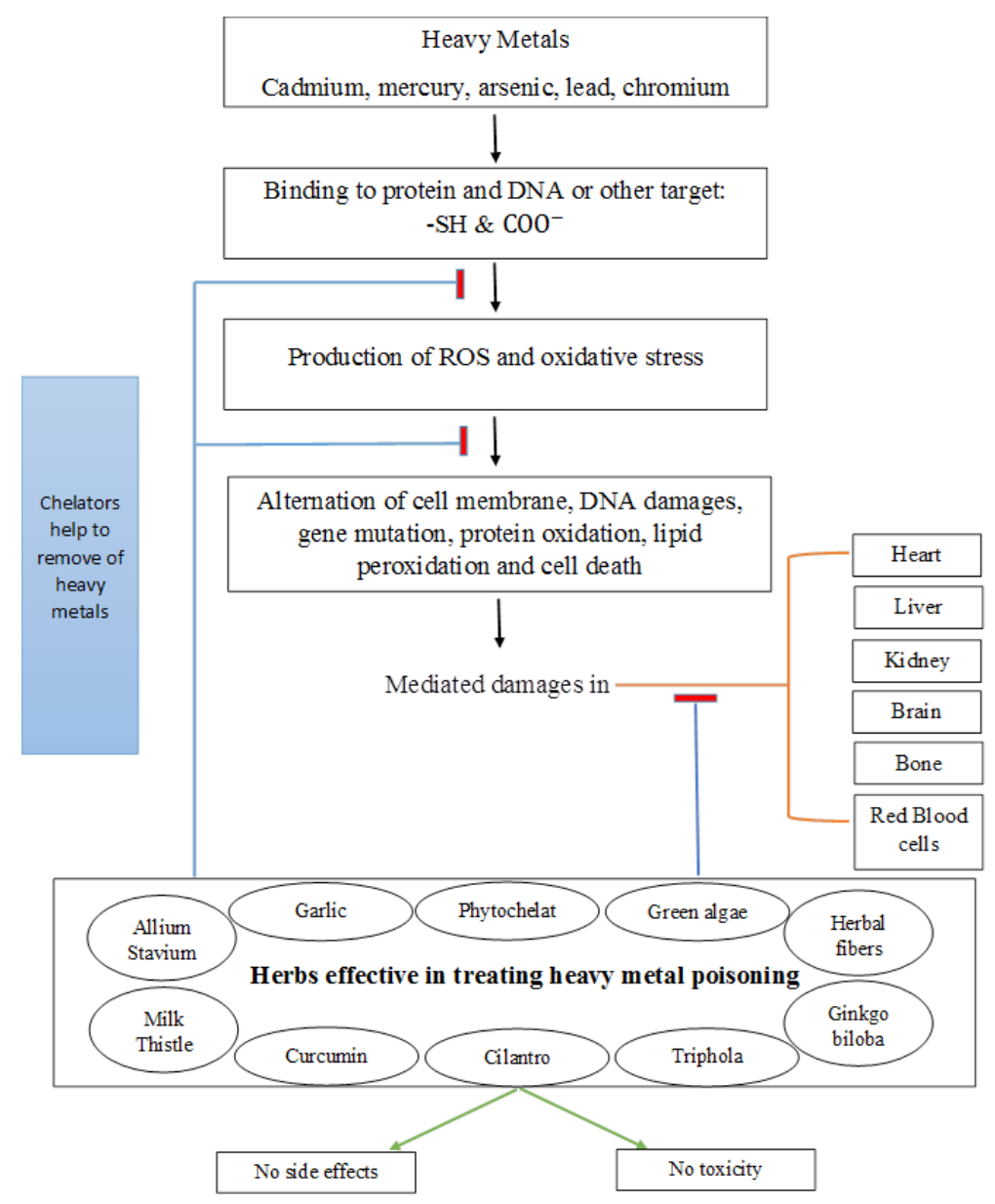

Figure 1. Mechanism of harmful effect of detrimental heavy metals in body and the subsequence defense presented by plants. 
defense presented by plants and supplements which are effective in treatment of heavy metal toxicity.

\section{Conclusion}

In summary, administration of chelating agents is the most common therapy for heavy metals toxicity. In addition of chemical compounds which are prescribed orally or injectable as chelating agents, some medicinal herbs can be used as the potential treatments for the heavy metals poisoning because of their fewer side effects. Our study showed that medicinal herbs including A. sativum (garlic), S. marianum (milk thistle), C. sativum (cilantro), Ginkgo biloba (gingko), C. longa (turmeric), phytochelatins, triphala, herbal fibers and Chlorophyta (green algae) can be considered as the potential treatments for the heavy metals poisoning.

\section{Author's contributions}

All the authors contributed in data collection and preparation of the manuscript. The first draft was prepared by RM. All authors read the final version and confirmed for the publication.

\section{Conflict of interests}

Authors declare there is not any conflict of interest.

\section{Ethical considerations}

Ethical issues have been observed by the authors.

\section{Funding/Support}

None.

\section{References}

1. Desoize B. Metals and metal compounds in cancer treatment. Anticancer Res. 2004;24(3a):1529-44.

2. Hubner R, Astin KB, Herbert RJ. 'Heavy metal'--time to move on from semantics to pragmatics? J Environ Monit. 2010;12(8):1511-4. doi: 10.1039/c0em00056f.

3. Lima E, Guerra R, Lara V, Guzman A. Gold nanoparticles as efficient antimicrobial agents for Escherichia coli and Salmonella typhi. Chem Cent J. 2013;7(1):11. doi: 10.1186/1752-153x-7-11.

4. Stern BR. Essentiality and toxicity in copper health risk assessment: overview, update and regulatory considerations. J Toxicol Environ Health A. 2010;73(2):114-27. doi: $10.1080 / 15287390903337100$.

5. Harvey LJ, McArdle HJ. Biomarkers of copper status: a brief update. Br J Nutr. 2008;99 Suppl 3:S10-3. doi: 10.1017/ s0007114508006806.

6. Duffus JH. "Heavy metals" a meaningless term? (IUPAC Technical Report). Pure Appl Chem. 2002; 74(5):793-807. doi: 10.1351/pac200274050793.

7. He ZL, Yang XE, Stoffella PJ. Trace elements in agroecosystems and impacts on the environment. J Trace Elem Med Biol. 2005;19(2-3):125-40. doi: 10.1016/j. jtemb.2005.02.010.

8. Beyersmann D, Hartwig A. Carcinogenic metal compounds: recent insight into molecular and cellular mechanisms.
Arch Toxicol. 2008;82(8):493-512. doi: 10.1007/s00204008-0313-y.

9. Flora SJ, Mittal M, Mehta A. Heavy metal induced oxidative stress $\&$ its possible reversal by chelation therapy. Alternative Medicine Review. 2009;14(1):87-8.

10. Lopez Alonso M, Prieto Montana F, Miranda M, Castillo C, Hernandez J, Luis Benedito J. Interactions between toxic (As, $\mathrm{Cd}, \mathrm{Hg}$ and $\mathrm{Pb}$ ) and nutritional essential $(\mathrm{Ca}, \mathrm{Co}, \mathrm{Cr}$, $\mathrm{Cu}, \mathrm{Fe}, \mathrm{Mn}, \mathrm{Mo}, \mathrm{Ni}, \mathrm{Se}, \mathrm{Zn}$ ) elements in the tissues of cattle from NW Spain. Biometals. 2004;17(4):389-97.

11. Tchounwou P. Development of public health advisories for arsenic in drinking water. Rev Environ Health. 1999;14(4):211-30.

12. Centeno JA, Tchounwou PB, Patlolla AK, Mullick FG, Murakata L, Meza E, et al. Managing Arsenic in the Environment: From Soil to Human Health. Australia: CSIRO Publishing; 2006:311-8.

13. Tchounwou PB, Centeno JA, Patlolla AK. Arsenic toxicity, mutagenesis, and carcinogenesis--a health risk assessment and management approach. Mol Cell Biochem. 2004;255(12):47-55.

14. Satarug S, Baker JR, Urbenjapol S, Haswell-Elkins M, Reilly PE, Williams DJ, et al. A global perspective on cadmium pollution and toxicity in non-occupationally exposed population. Toxicol Lett. 2003;137(1-2):65-83.

15. Mukherjee S, Das SK, Kabiru W, Russell KR, Greaves K, Ademoyero AA, et al. Acute cadmium toxicity and male reproduction. Adv Reprod. 2002;6(3-4):76.

16. Smith JB, Dwyer SD, Smith L. Lowering extracellular $\mathrm{pH}$ evokes inositol polyphosphate formation and calcium mobilization. J Biol Chem. 1989;264(15):8723-8.

17. Shelnutt SR, Goad P, Belsito DV. Dermatological toxicity of hexavalent chromium. Crit Rev Toxicol. 2007;37(5):375-87. doi: 10.1080/10408440701266582.

18. Goulart M, Batoreu MC, Rodrigues AS, Laires A, Rueff J. Lipoperoxidation products and thiol antioxidants in chromium exposed workers. Mutagenesis. 2005;20(5):3115. doi: 10.1093/mutage/gei043.

19. Flora SJ, Saxena G, Gautam P, Kaur P, Gill KD. Response of lead-induced oxidative stress and alterations in biogenic amines in different rat brain regions to combined administration of DMSA and MiADMSA. Chem Biol Interact. 2007;170(3):209-20. doi: 10.1016/j.cbi.2007.08.003.

20. Zahir F, Rizwi SJ, Haq SK, Khan RH. Low dose mercury toxicity and human health. Environ Toxicol Pharmacol. 2005;20(2):351-60. doi: 10.1016/j.etap.2005.03.007.

21. Valko M, Izakovic M, Mazur M, Rhodes CJ, Telser J. Role of oxygen radicals in DNA damage and cancer incidence. Mol Cell Biochem. 2004;266(1-2):37-56. doi: 10.1023/b:mc bi.0000049134.69131.89.

22. Flora SJ, Pachauri V. Chelation in metal intoxication. Int J Environ Res Public Health. 2010;7(7):2745-88. doi: 10.3390/ijerph7072745.

23. Trevor AJ, Katzung BG, Masters SB, Kruidering-Hall M. Pharmacology Examination \& Board Review. New York: McGraw-Hill Medical; 2010:469-83.

24. De Smet PAGM, Keller K, Hansel R, Frank Chandler R. Adverse Effects of Herbal Drugs. Germany: Springer; 1992:1-13.

25. Abdalla FH, Belle LP, De Bona KS, Bitencourt PE, Pigatto AS, Moretto MB. Allium sativum L. extract prevents 
methyl mercury-induced cytotoxicity in peripheral blood leukocytes (LS). Food Chem Toxicol. 2010;48(1):417-21. doi: $\quad 10.1016 /$ j.fct.2009.10.033.

26. Lampe JW, Peterson S. Brassica, biotransformation and cancer risk: genetic polymorphisms alter the preventive effects of cruciferous vegetables. J Nutr. 2002;132(10):29914. doi: $10.1093 /$ jn/131.10.2991.

27. Cha CW. A study on the effect of garlic to the heavy metal poisoning of rat. J Korean Med Sci. 1987;2(4):213-24. doi: 10.3346/jkms.1987.2.4.213.

28. Nwokocha CR, Owu DU, Nwokocha MI, Ufearo CS, Iwuala MO. Comparative study on the efficacy of Allium sativum (garlic) in reducing some heavy metal accumulation in liver of Wistar rats. Food Chem Toxicol. 2012;50(2):222-6. doi: 10.1016/j.fct.2011.11.003.

29. Senapati SK, Dey S, Dwivedi SK, Swarup D. Effect of garlic (Allium sativum L.) extract on tissue lead level in rats. J Ethnopharmacol. 2001;76(3):229-32.

30. Borsari M, Gabbi C, Ghelfi F, Grandi R, Saladini M, Severi $\mathrm{S}$, et al. Silybin, a new iron-chelating agent. J Inorg Biochem. 2001;85(2-3):123-9.

31. Wellington K, Jarvis B. Silymarin: a review of its clinical properties in the management of hepatic disorders. BioDrugs. 2001;15(7):465-89. doi: 10.2165/00063030200115070-00005

32. Tunali-Akbay T, Sener G, Salvarli H, Sehirli O, Yarat
A. Protective effects of Ginkgo biloba extract against mercury(II)-induced cardiovascular oxidative damage in rats. Phytother Res. 2007;21(1):26-31. doi: 10.1002/ ptr.2007.

33. Hewlings S, Kalman D. Curcumin: a review of its' effects on human health. Foods. 2017;6(10):E92. doi: 10.3390/ foods6100092.

34. Vatamaniuk OK, Bucher EA, Ward JT, Rea PA. A new pathway for heavy metal detoxification in animals. Phytochelatin synthase is required for cadmium tolerance in Caenorhabditis elegans. J Biol Chem. 2001;276(24):2081720. doi: 10.1074/jbc.C100152200.

35. Cobbett CS. Phytochelatins and their roles in heavy metal detoxification. Plant Physiol. 2000;123(3):825-32.

36. Belapurkar P, Goyal P, Tiwari-Barua P. Immunomodulatory effects of triphala and its individual constituents: a review. Indian J Pharm Sci. 2014;76(6):467-75.

37. Rafati-Rahimzadeh M, Rafati-Rahimzadeh M, Kazemi S, Moghadamnia AA. Current approaches of the management of mercury poisoning: need of the hour. Daru. 2014;22:46. doi: 10.1186/2008-2231-22-46.

38. Uchikawa T, Kumamoto Y, Maruyama I, Kumamoto S, Ando Y, Yasutake A. Enhanced elimination of tissue methylmercury in Parachlorella beijerinckii-fed mice. J Toxicol Sci. 2011;36(1):121-6. 